\title{
Motivating Medical Students Using Virtual Reality Based Education
}

\author{
https://doi.org/10.3991/ijet.v15i02.11394 \\ Mian Usman Sattar ${ }^{(凶)}$ \\ Malaysia University of Science and Technology, Kuala Lumpur, Malaysia \\ University of Management and Technology, Lahore, Pakistan \\ usman.sattar@umt.edu.pk \\ Sellappan Palaniappan, Asiah Lokman \\ Malaysia University of Science and Technology, Kuala Lumpur, Malaysia \\ Nauman Shah, Usman Khalid \\ University of Management and Technology, Lahore, Pakistan \\ Raza Hasan \\ Malaysia University of Science and Technology, Kuala Lumpur, Malaysia
}

\begin{abstract}
An exploratory study to compare the effects of immersive virtual reality based training on the learning motivation of final year medical students as compared to video and text-based learning. Different modes of delivery of a training simulation of laparoscopy operation were presented to students and learning motivation corresponding to which were evaluated using the Intrinsic Motivation Inventory. Undergraduate medical students from 8 medical colleges and universities across Pakistan participated in this study. A total of 87 students with a mean age of $22.5 \pm 4$ years were recruited for the study. Of these, $57.4 \%$ $(n=50)$ were males and $42.6 \%(n=37)$ were females. Paired sampled t-test was chosen for the statistical investigation for the study. The tests were conducted by comparing means of text, video, and virtual reality learning methodologies in medical students. All applied statistical models have significance value $p=0.00$ indicating a significant difference. Medical student motivation was observed to be the greatest in Virtual Reality settings as compared to videobased and text-based learning settings. Both theoretical and practical studies have importance in medical studies, whereas practical hand-on-practice can enhance medical students' professional proficiency. Virtual reality was at the top in User experience, perceived competence, usefulness, and motivation for final year medical students. It can play a signficant role in contemporary teaching and learning methodology with medical educationist and students can get benefit from this technology.
\end{abstract}

Keywords - Virtual Reality (VR), Learning Motivation, Medical Simulations, Intrinsic Motivation Inventory (IMI) 


\section{Introduction}

The rapid change and improvement in technology have revolutionized the modern world. Human-Computer Interaction (HCI) has advanced over a period transforming many aspects of our lives, including the way we learn [1]. Students, nowadays, can benefit from the quick exchange of information, online accessibility, and practical implementation of what was previously only being taught in the books. The learning experience and competency are dependent upon how well a subject is delivered to the students and through which medium [2]. Books and text-based resources have proven, over time, to be an excellent mode of delivery and have been used for centuries. However, with the upcoming advancements of technology, it is now deemed outdated [3].

Audio and video-based resources have also proven to be an effective mode of delivery as they provide a good amount of rich content in a relatively shorter period, which has led to an increase in the student's motivation in class [4] and a change in perception of educators [5]. However, the lack of immersion and control makes videobased learning less personal than interactive classrooms and real-life simulations [6]. In the field of medicine, however, real-life simulations are not always easy to setup. Virtual Reality (VR), in such cases, has proven to be a very effective tool to deliver rich content in an immersive environment [7].

\subsection{Virtual reality technology}

VR is an interactive computer-generated experience taking place within a simulated environment. Its primary effect is to place the user into the simulated environment using a head-mounted display. Its users are provided with a sense of self-location within the environment through mapping the head-movement with the synthetic world, allowing them experience a sense of immersion as they explore the virtual world around them. This spatial immersion into the virtual environment with an objective level of sensory fidelity is dependent on the system's software and hardware limitations. Presence, however, is the user's subjective response to the VR system which can be different from user to user [8].

Spatial immersion or the sense of 'being there' into virtual reality created by surrounding the user with dynamically generated audio, visuals and other sensory stimuli provide a very absorbing environment. it.

In immersive VR, 3D rendered objects appear solid and have an egocentric location much like real objects in real world. Objects can be manipulated using special input devices, allowing users to not only experience the simulated environment but also interact with it [9].

The fundamental limitation to all these effects is in the computational technology that supports them. As technological capabilities advance, VR has evolved in several manners itself becoming more and more similar to the real world. ICT and VR have become strictly interconnected as computing power increases, a bigger part of population adopting it with its use making its way into different fields. 


\subsection{Virtual reality in training and education}

In addition to the more obvious use of VR technology in the entertainment field, VR is also widely being used in the fields of education and training. VR is generally associated with high-user engagement due to its potentials is stimulating interactivity [10] and motivation [11][12]. Moreover, the visual, audio, and kinaesthetic sensory stimuli offer a higher dimension of information absorption [13].

VR is often used in occupational training where the workers need to be exposed to scenarios that are difficult or dangerous to recreate. In these cases, VR provides a risk-free simulation where users can achieve hands on practice before moving on to the real task. Such examples include an immersive learning environment to teach the US army soldiers basic corrosion prevention and control knowledge [14]. Aviation students are taught how to land an aircraft in a simulated environment before moving on to the real world. Similarly, construction workers have been taught how to make well-balanced structures through VR applications [15]. Similarly, VR provides an effective platform to train young doctors immersing them in life-like scenarios allowing them to practice and observe with no real consequences. The immersive environments capture the student's attention leading to higher learning outcomes [16].

Medical education often involves teaching complex procedures which have to be effectively taught and communicated to the students [17]. With advancements in the field of medicine and its increasing complexity, the processes have become harder for the students to understand. Simple text-based learning or video-based learning is not enough, and hands-on practice on practical exercises is needed. However, this is dependent on the availability of resources, cost, and risk [18].

In order to train students in a more realistic yet less risky way, VR shows great potential to do so [19]. Students can be placed in an immersive environment where not only they can observe more in detail, but can also feel the real sense of what it's like to be in the operation theatre [20]. Moreover, VR scenarios can reduce the setup cost and risk, for even if a student makes an error, there are no real-life consequences [21]. Additionally, VR allows recreation of certain scenarios which might not be possible or difficult to recreate in real life, which can cater to ensuring better delivery of, what is known as, blended curriculum [22].

Blending curriculum with technological tools such as VR can improve students' motivation, in turn, affecting their academic and practical performance [23]. This research is mainly focused on virtual reality, and other related technologies which have helped the medical students in a better learning of their coursework, a better understanding, and have increased the learning competencies of the students [24]. The paper is focused on some VR-based medical applications that have taught the students from the basics of the human body to advanced simulated surgical operations [25].

\section{Research Hypothesis}

Cited below were the suggested hypothesis carried out by the authors. To determine the truthfulness of the research hypothesis, the experiment has been conducted. 
H1: Learning competency and motivation of the medical participants during textbased learning methodology will relatively be lower than VR based learning methodology.

H2: Learning competency and motivation of the medical participants during videobased learning methodology will relatively be lower than VR based learning methodology.

H3: Learning competency and motivation of the medical participants during textbased learning methodology will relatively be lower than video-based learning methodology.

H4: Medical participants' learning experience and usefulness during text-based learning methodology will relatively be lower than VR based learning methodology.

H5: Medical participants' learning experience and usefulness during video-based learning methodology will relatively be lower than VR based learning methodology.

H6: Medical participants' learning experience and usefulness during text-based learning methodology will relatively be lower than video-based learning methodology.

\section{$3 \quad$ Material and Methods}

For this research, different tools were used to understand the text, video, and VR based learning-based methodology. Laparoscopy operation has been taken as a sample to experiment conventional and VR based learning methodology. All three learning methodologies and their sample material have been carefully selected \& reviewed by an assistant professor and an MBBS doctor before the start of the experiment. In text, authors prepared a sample text file based on different materials that includes book review, article reading, teaching materials, video materials from YouTube and Medical Reality app whereas during video-based learning carefully shortlists a sample visual similar to text and VR material from YouTube and lastly during virtual reality based learning, Medical Reality VR app has been used to highlight all key parameters for the experiment. MR is a mobile-based virtual reality app available in both Android and iOS, providing medical training at both graduate and undergraduate level. Individuals can have a real-time experience of this VR app by mounting VR gear like Oculus Rift, Samsung Gear VR, Cardboard (iOS and Android), HTV Vive, and Google Daydream. This app is further divided into various categories associated with much medical training, enrich with effective curriculum quality.

To determine the effects of participants' learning motivation, learning competency, learning experience, and usefulness; a questionnaire was designed by the first author after proofreading and approval of the sample material by senior practitioners. This strategy helped the participant to get an in-depth understanding of the medical scenario. 


\section{Experimental Set-up}

Text-based, video based and VR based Learning methodologies have been selected for the experiment whereas similar teaching materials of laparoscopy operation for each learning methodology have also been prepared. 87 volunteers, 50 male and 37 female participants with mean age group of $\sim 22.5 \pm 4$ years from three public and five private medical and dental college of Punjab, Pakistan have participated in this research. Response percentage by gender is depicted in Figure 1. The study was announced and willing participants were recruited by signing a consent form. The study is segmented into three major segments, with each segment based on a specific mode of delivery; text, video and VR.

\section{Gender}

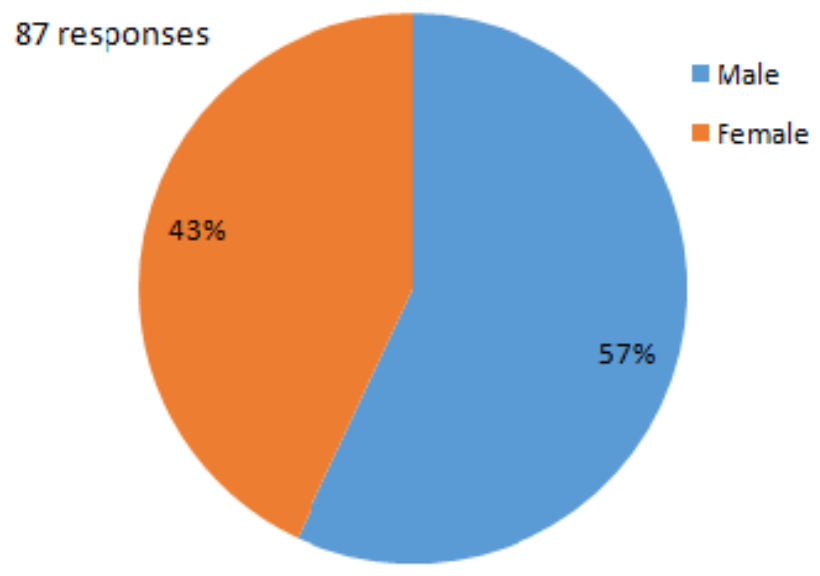

Fig. 1. Responses by Gender

Student motivation was evaluated using pre-validated surveys adapted from Intrinsic Motivation Inventory (IMI) [26], [27] filled by the student after each segment. The survey covers four categories with four questions in each. The survey has two parts. In the first part demographic information is collected and in the second a Likert scale of 1 to 7 is used for getting responses. 1 means "strongly disagreement" and 7 means "strongly agreement" with the statement. Each respondent averagely spent 2.37 minutes in video, 1.27 minutes in text and 2 minutes at virtual reality based learning.

Consent form was signed by each participant ensuring that they are voluntarily participating in the experiment. To get more authentic results, the experiment has been conducted with a random sequence of the segments chosen by the author and the doctor. It was mandatory for all participants to complete all segments. 2 .

Response percentage of eight medical colleges and universities is depicted in figure 
Responses from Institutations

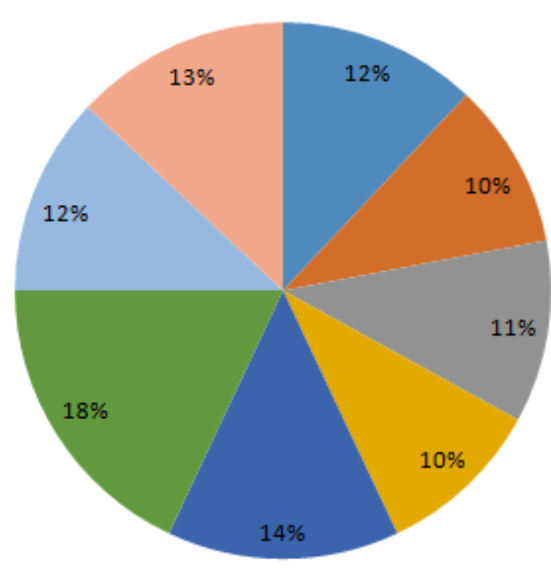

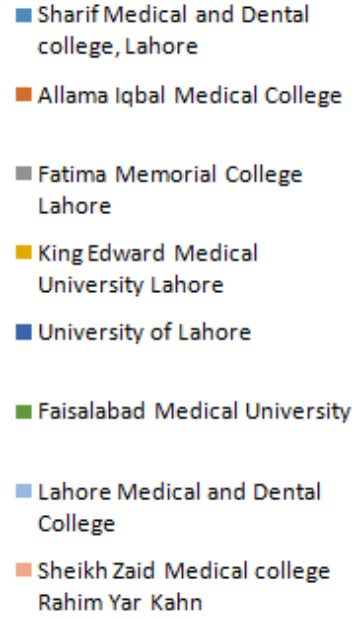

Fig. 2. Response Percentage from Institution

Following are the description of all the segments:

\subsection{Segment one - Text based learning methodology}

During the experiment while using text based learning methodology, the author under the supervision of the practitioner provided briefing of text based learning and the task to be performed. As this is the conventional way of learning, participants easily understood the requirement. Participants were then provided with a hand-out of an anatomy experiment text file. The content of the hardcopy text file, the video and the virtual reality app were all similar. The average time taken by the participants to read the text file was 3 minutes. After completion of the reading the hand-out, participants were then advised to fill out the questionnaire expressing their learning motivation, competency, experience and usefulness during this text based learning methodology.

\subsection{Segment two - Video based learning methodology}

During the experiment while using video-based learning methodology, the author under the supervision of the practitioner provided the briefing of the video based learning and the task to be performed during this segment. As this is also considered to be as conventional way of learning participants easily understand the experiment and how to perform. Participants were then provided with the video of anatomy experiment from YouTube.

The content of video was similar to the text and virtual reality app but it contained sounds and high definition visuals. The video highlighted key notes of anatomy and laparoscopy operations. The average time taken by the participants to watch the video was 1.40 minutes. After watching the video participants were then advised to fill out 
the questionnaire expressing their learning motivation, competency, experience and usefulness during their Video based learning methodology.

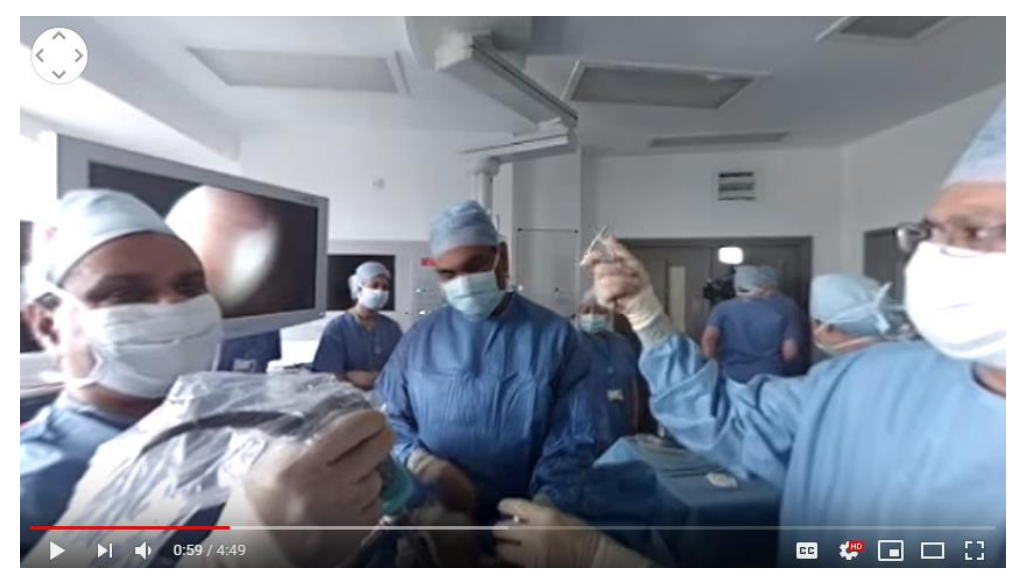

Fig. 3. Video Based Learning Methodology View

Pictorial view of video based learning methodology can be viewed in figure 3 .

\subsection{Segment three - Virtual reality/ simulation based}

Learning methodology: Similar to previous stages, during the virtual based learning methodology; the author under the supervision of the practitioner provided a briefing VR based learning and the task to be performed. As this is not a conventional way of learning; participants required more explanation to understand the requirement.

The experiment started with participants being provided with the Mobile mounted Samsung Oculus Gear VR glasses. The mobile contained the android version of Medical Reality (MR) app. App navigation and categories were explained to each participant.

The content of MR app was similar to video and text based Learning but in VR participant could have 360 degree view of laparoscopy surgical operation. 

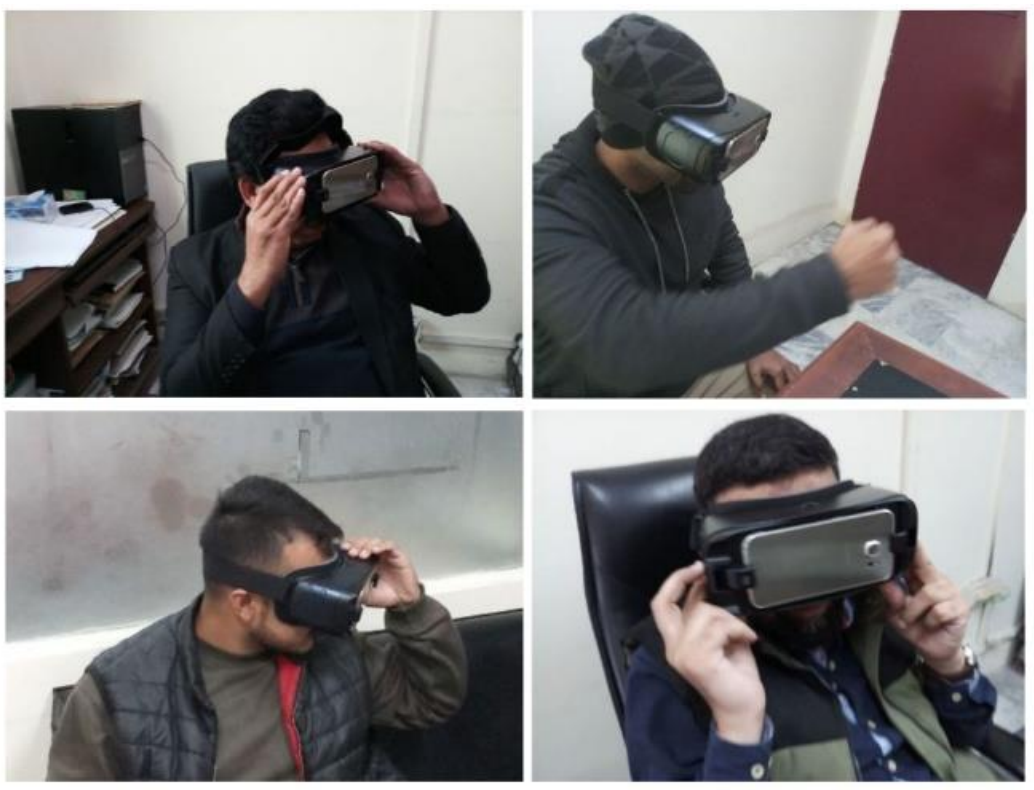

Fig. 4. MBBS Final Year Students Experiencing VR

Experience of VR based learning methodology can be observed in figure 4. Moreover, MR app was self-explained highlighting the key notions, important parts of anatomy and laparoscopy operation. In order to get the real-time environment and satisfactory experience each participant was advised to use MR app for at least 4 minutes.
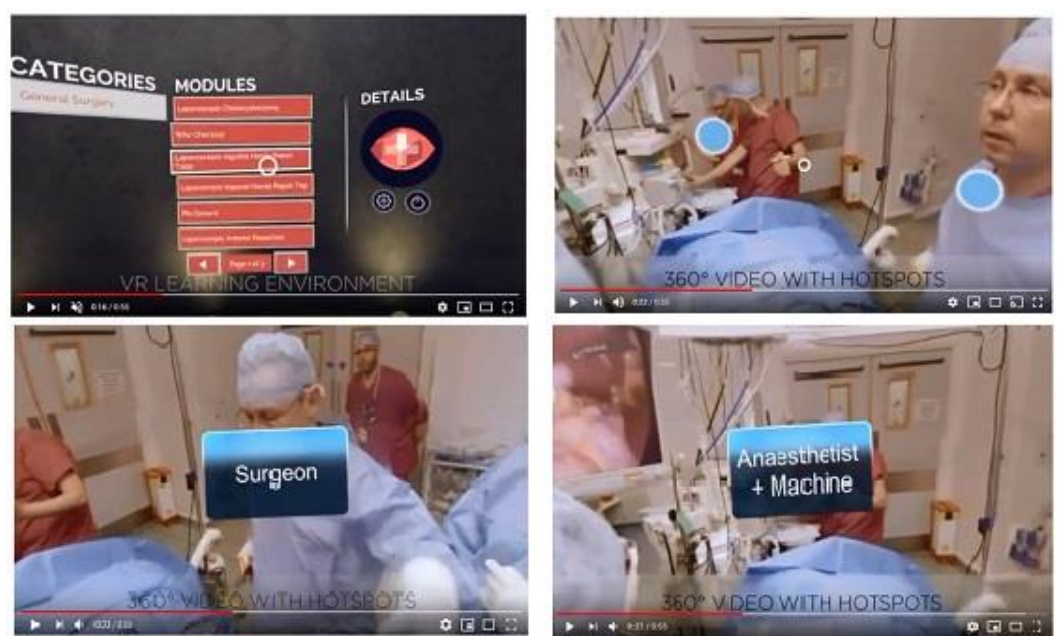

Fig. 5. Virtual Reality Environment 
Different screen shorts during experience of virtual reality application are available in figure 5. Following abbreviation are being used MVRL for mean of virtual reality learning motivation, MVRC for mean of virtual reality learning competency, MTXL for mean of text based learning motivation, MTXC for mean of text based learning competency, MVIL for mean of video based learning motivation and MVIC for mean of video based learning competency.

\section{$5 \quad$ Results}

For hypothesis verification paired sample t-test was selected. Before applying all assumption of t-test were verified.

Table 1. Mean Difference of Learning Competency

\begin{tabular}{|c|l|c|c|c|c|}
\hline Sr. No. & \multicolumn{1}{|c|}{ Mean Difference } & Value & SD & t-Value & P-Value \\
\hline 1. & MVRC-MTXC & 0.69505 & 0.92256 & 7.187 & 0.000 \\
\hline 2. & MVRC-MVIC & 1.68132 & 1.14690 & 13.984 & 0.000 \\
\hline 3. & MTXC-MVIC & 0.98626 & 1.30882 & 7.188 & 0.000 \\
\hline
\end{tabular}

Mean difference of MVRC-MTXC, is 0.69505 with SD 0.92256. The paired sample t test-statistic value is 7.187 with p-value 0.000 which is less than 0.05 . Mean MVRC is significantly differing from Mean MTXC. Mean difference of MVRCMVIC, is 1.68132 with SD 1.14690. The paired sample t test-statistic value is 13.984 with p-value 0.000 which is less than 0.05 . Mean MVRC is significantly differing from Mean MVIC. Mean difference of MTXC-MVIC, is 0.98626 with SD 1.30882. The paired sample t test-statistic value is 7.188 with $\mathrm{P}$-value 0.000 which is less than 0.05. Mean MTXC is significantly differing from Mean MVIC. All these explained means values of learning competencies are shown in table 1.

Table 2. Mean Difference of Learning Motivation

\begin{tabular}{|c|l|c|c|c|c|}
\hline Sr. No. & \multicolumn{1}{|c|}{ Mean Difference } & Value & SD & t-Value & P-Value \\
\hline 1. & MVRL-MTXL & 0.63462 & 0.86386 & 7.008 & 0.000 \\
\hline 2. & MVRL-MVIL & 1.24451 & 1.00414 & 11.823 & 0.000 \\
\hline 3. & MTXL-MVIL & 0.60989 & 1.16560 & 4.991 & 0.000 \\
\hline
\end{tabular}

Mean difference of MVRL-MTXL, is 0.63462 with SD 0.86386. The paired sample $t$ test-statistic value is 7.008 with p-value 0.000 which is less than 0.05 . Mean MVRL is significantly differing from Mean MTXL. Mean difference of MVRLMVIL, is 1.24451 with SD 1.00414. The paired sample t test-statistic value is 11.823 with p-value 0.000 which is less than 0.05 . Mean MVRL is significantly differing. 


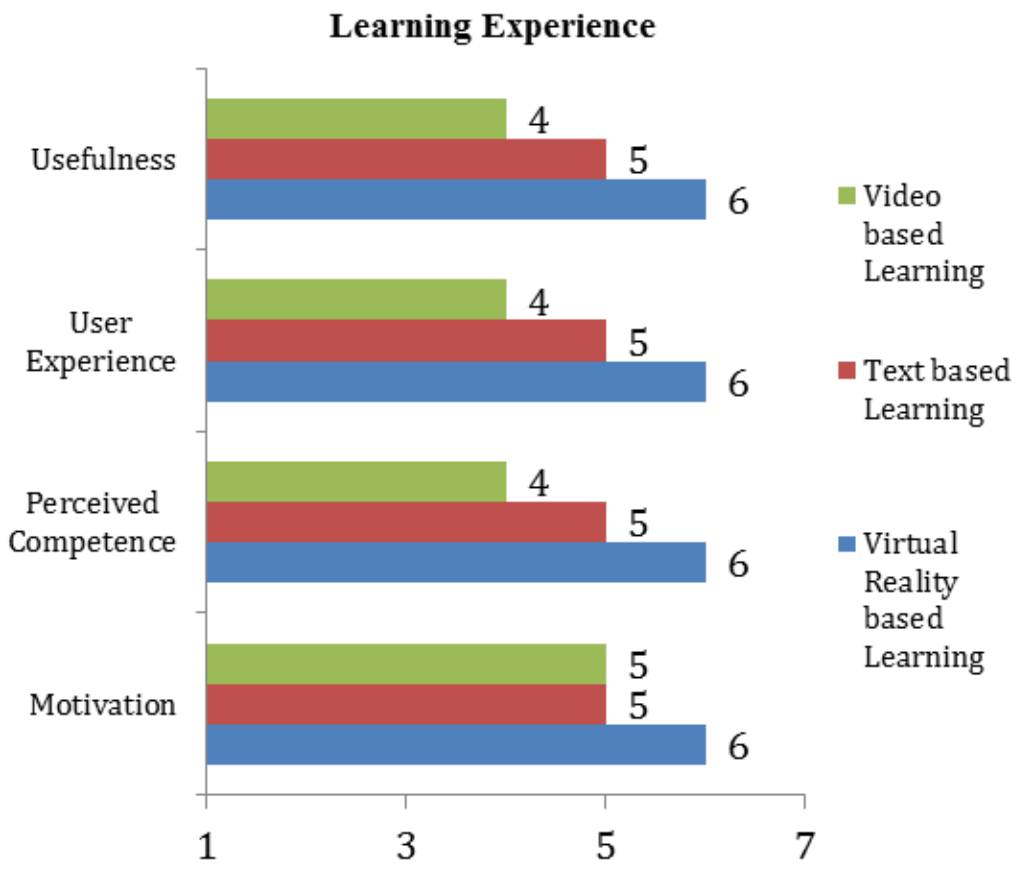

Fig. 6. Comparison of Learning Methodologies

Mean difference of MTXL-MVIL, is .60989 with SD 1.16560. The paired sample t test-statistic value is 4.991 with p-value 0.000 which is less than 0.05. Mean MTXL is significantly differing from Mean MVIL. All these explained means values of learning motivations are shown in table 2.

In usefulness mean values of virtual reality is highest in comparison of text and video-based learning. Text-based learning stands at the second level. In user experience and perceived competence, the results are the same as usefulness. Virtual reality has the highest value among text and video-based learning. Medical students learning motivation during text and video-based learning is same while learning through VR based learning is highest among others.

\section{Discussion}

The use of VR in the educational sector is new and there is a lot to be explored in regards to its impact. One of the major purposes of this experiment was to investigate the students' perception of VR application for education.

In this study, we explored the impact of using VR to train young students. Figure 6 showed the mean comparison of usefulness, user experience, perceived competence and motivation through video, virtual reality, and text-based learning.

We see a significant increase in the usefulness when using VR in comparison to other pedagogies. The usefulness scale implies that the students consider the task of 
some value to them hence feel motivated to learn. The VR environment presented in the application puts the students into the operation theatre allowing them to observe the procedure closely with tooltips graphical interface explaining the procedure and equipment. This sense of presence and added layers give the students a better understanding of the procedure, something lacking in the text or video-based learning.

Moreover, providing students with an environment where they can explore their curiosities without risk and observe critical procedures closely significantly increases the student's perceived competence as can be seen in Figure 6.

Furthermore, while using VR as the mode of delivery of learning material for students, the sense of immersion, interactivity and the multi-modal sensory stimuli provided by it has significantly increased the learning experience of students.

Lastly, it can be seen that the students feel more motivated towards learning through VR.

\section{Conclusion and Future Directions}

VR can offer great advantages for learning as its immersive characteristic offers a sense of presence with a direct feeling of objects and environments that might be difficult to achieve in real life. It supports education and training in a risk-free environment, and with the diverse variety of applications. In this study, we developed a VR medical training application and tested its impact on student's motivation, learning competency, user experience, and perceived competence.

The experiment was conducted in 8 medical colleges and universities with participation from 87 students. The statistical analysis concludes that $\mathrm{H} 1, \mathrm{H} 2, \mathrm{H} 4, \mathrm{H} 5$ are accepted whereas $\mathrm{H} 3$ and $\mathrm{H} 6$ are rejected. In comparison, VR is higher in all four studied aspects. As per discussions and results of the above statistical tests.

The research adds sets down a solid foundation for the use VR in the education and training sector, especially in the field of medicine, where the risk is high. Virtual reality is found more suitable in terms of user experience, usefulness, as learning methodology and for learning competency in comparison to other conventional modes of delivery. Both medical educationist and students may initiate immersive technologies for professional curriculum learning.

In future, other immersive technologies such as augmented reality and mixed reality can be experienced to explore further dimension in medical students learning. Moreover, future researchers are recommended to explore the impact of immersive educational application on the performances of students.

\section{$8 \quad$ References}

[1] K. Ahmad, O. Mohammad, M. Atieh, and H. Ramadan, "Enhanced Performance and Faster Response using New IoT LiteTechnique,” Int. Arab J. Inf. Technol., vol. 16, no. 3, pp. 548-556, 2019. 
[2] A.-K. Masum, L.-S. Beh, A.-K. Azad, and K. Hoque, "Intelligent human resource information system (i-HRIS): A holistic decision support framework for HR excellence," Int. Arab J. Inf. Technol., vol. 15, no. 1, pp. 121-130, 2018.

[3] D. A. Back, J. von Malotky, K. Sostmann, R. Hube, H. Peters, and E. Hoff, "Superior Gain in Knowledge by Podcasts Versus Text-Based Learning in Teaching Orthopedics: A Randomized Controlled Trial," J. Surg. Educ., vol. 74, no. 1, pp. 154-160, Jan. 2017. https:// doi.org/10.1016/j.jsurg.2016.07.008

[4] E. Bravo, B. Amante, P. Simo, M. Enache, and V. Fernandez, "Video as a new teaching tool to increase student motivation," in 2011 IEEE Global Engineering Education Conference (EDUCON), 2011, pp. 638-642. https://doi.org/10.1109/educon.2011.5773205

[5] M. Kalogiannakis and S. J. Papadakis, "The Dual Form of Further Education of Educators In ICT: Technological and Pedagogical Training," in 8th International Conference On Computer Based Learning in Science (CBLIS 2007), 2007.

[6] V. Abaidoo and N. Arkorful, "The role of e-learning, advantages and disadvantages of its adoption in higher education," Int. J. Instr. Technol. Distance Learn., vol. 2, no. 12, p. 7, 2015.

[7] D. Healey, "Technology Enhanced Learning Environments," in The TESOL Encyclopedia of English Language Teaching, vol. 24, no. 4, Hoboken, NJ, USA: John Wiley \& Sons, Inc., 2018, pp. 1-6. https://doi.org/10.1002/9781118784235.eelt0437

[8] D. A. Bowman and R. P. McMahan, "Virtual Reality: How Much Immersion Is Enough?," Computer (Long. Beach. Calif)., vol. 40, no. 7, pp. 36-43, Jul. 2007. https://doi.org/10.11 09/mc.2007.257

[9] J. Psotka, "Immersive training systems: Virtual reality and education and training," Instr. Sci., vol. 23, no. 5-6, pp. 405-431, Nov. 1995. https://doi.org/10.1007/bf00896880

[10] M. Roussou, "Learning by doing and learning through play," Comput. Entertain., vol. 2, no. 1, p. 10, Jan. 2004.

[11] R. Garris, R. Ahlers, and J. E. Driskell, "Games, Motivation, and Learning: A Research and Practice Model," Simul. Gaming, vol. 33, no. 4, pp. 441-467, Dec. 2002. https://doi. org/10.1177/1046878102238607

[12] M. Ott and M. Tavella, "A contribution to the understanding of what makes young students genuinely engaged in computer-based learning tasks," Procedia - Soc. Behav. Sci., vol. 1, no. 1, pp. 184-188, 2009. https://doi.org/10.1016/j.sbspro.2009.01.034

[13] W. L. Leite, M. Svinicki, and Y. Shi, "Attempted Validation of the Scores of the VARK: Learning Styles Inventory With Multitrait-Multimethod Confirmatory Factor Analysis Models," Educ. Psychol. Meas., vol. 70, no. 2, pp. 323-339, Apr. 2010. https://doi.org/ $10.1177 / 0013164409344507$

[14] R. D. Webster, "Corrosion prevention and control training in an immersive virtual learning environment," NACE - Int. Corros. Conf. Ser., no. June, 2014.

[15] C. Fowler, "Virtual reality and learning: Where is the pedagogy?," Br. J. Educ. Technol., vol. 46, no. 2, pp. 412-422, Mar. 2015. https://doi.org/10.1111/bjet.12135

[16] J. Bertram, J. Moskaliuk, and U. Cress, "Virtual training: Making reality work?," Comput. Human Behav., vol. 43, pp. 284-292, Feb. 2015. https://doi.org/10.1016/j.chb.2014.10.032

[17] F. Pucciarelli and A. Kaplan, "Competition and strategy in higher education: Managing complexity and uncertainty," Bus. Horiz., vol. 59, no. 3, pp. 311-320, May 2016. https:// doi.org/10.1016/j.bushor.2016.01.003

[18] F. A. Haji, D. Rojas, R. Childs, S. de Ribaupierre, and A. Dubrowski, "Measuring cognitive load: performance, mental effort and simulation task complexity," Med. Educ., vol. 49, no. 8, pp. 815-827, Aug. 2015. https://doi.org/10.1111/medu.12773 
[19] C. Moro, Z. Štromberga, A. Raikos, and A. Stirling, "The effectiveness of virtual and augmented reality in health sciences and medical anatomy," Anat. Sci. Educ., vol. 10, no. 6, pp. 549-559, Nov. 2017. https://doi.org/10.1002/ase.1696

[20] S. Nuanmeesri, "The Augmented Reality for Teaching Thai Students about the Human Heart,” Int. J. Emerg. Technol. Learn., vol. 13, no. 06, p. 203, May 2018. https://doi.org/ 10.3991/ijet.v13i06.8506

[21] J. M. Wagner, A. E. Fleming, K. F. Moynahan, M. G. Keeley, I. H. Bernstein, and R. B. Shochet, "Benefits to faculty involved in medical school learning communities," Med. Teach., vol. 37, no. 5, pp. 476-481, May 2015. https://doi.org/10.3109/0142159x.2014.947 $\underline{940}$

[22] M. Hussein and C. Natterdal, "The Benefits of Virtual Reality in Education: A Comparison Study," 2015.

[23] N. Elmqaddem, "Augmented Reality and Virtual Reality in Education. Myth or Reality?," Int. J. Emerg. Technol. Learn., vol. 14, no. 03, p. 234, Feb. 2019. https://doi.org/10.3991/ ijet.v14i03.9289

[24] K. E. Stavroulia and A. Lanitis, "Enhancing Reflection and Empathy Skills via Using a Virtual Reality Based Learning Framework," Int. J. Emerg. Technol. Learn., vol. 14, no. 07, p. 18, Apr. 2019. https://doi.org/10.3991/ijet.v14i07.9946

[25] M. U. Sattar, S. Palaniappan, A. Lokman, A. Hassan, N. Shah, and Z. Riaz, "Effects of Virtual Reality training on medical students' learning motivation and competency," Pakistan J. Med. Sci., vol. 35, no. 3, May 2019. https://doi.org/10.12669/pjms.35.3.44

[26] E. McAuley, T. Duncan, and V. V. Tammen, "Psychometric Properties of the Intrinsic Motivation Inventory in a Competitive Sport Setting: A Confirmatory Factor Analysis," Res. Q. Exerc. Sport, vol. 60, no. 1, pp. 48-58, Mar. 1989. https://doi.org/10.1080/0270 1367.1989 .10607413

[27] E. L. Deci, H. Eghrari, B. C. Patrick, and D. R. Leone, "Facilitating Internalization: The Self-Determination Theory Perspective,” J. Pers., vol. 62, no. 1, pp. 119-142, Mar. 1994. https://doi.org/10.1111/j.1467-6494.1994.tb00797.x

\section{Authors}

Mian Usman Sattar has fifteen years of training and consultancy experience in the fields of Information System. Usman has done MS (IT Management) from University of Sunderland, United Kingdom. His research interests are immersive and enterprise technologies. He is currently working as Assistant Professor at University of Management and Technology, Pakistan.

Dr. P. Sellappan is currently Professor of Information Technology, Dean of School of Science and Engineering, and Provost of the Malaysia University of Science and Technology. He holds MSc (CS) from University of London, and $\mathrm{PhD}$ from University of Pittsburgh. His research areas include Data Mining, Machine Learning, IoT, and Information Security.

Dr Asiah Lokman received her Bachelors in Telecommunication Engineering and MSc Engineering (EDFA fiber laser) in 2006 and 2012 from University of Malaya. In 2016, she receive PhD from University of Malaya (Photonics). Her fields of expertise are in Photonics, Computer Networking and Telecommunication.

Dr. Nauman Shah has done his PhD in Computer Science from University of Hertfordshire where he worked as a research associate for a European Commission- 
funded project, Supervised Care and Rehabilitation Involving Personal Tele-Robotics (SCRIPT). With extensive experience in using serious games to make training more immersive, engaging and motivating, Nauman aims to bring an innovative change in the education system by providing an interactive and immersive teaching environment. His research interests include gamification of Information Systems training modules to provide simulation based experience to the students.

Usman Khalid has done his MS in Business Information Management and Systems from La Trobe University Australia. He has worked in the industry as a process engineer and a quality auditor. He is an instructor at the University of Management and Technology with interest areas in Enterprise Resource Planning Systems, Big Data Analytics, Management Information Systems and Data mining.

Raza Hasan received his B.S. (Computer Science) from Khadim Ali Shah Bukhari Institute of Technology (KASBIT), Karachi, Pakistan in 2004. He received Masters in Forensic Computing from Staffordshire University UK in 2007. Currently, he is pursuing Doctor of Philosophy in Informatics from Malaysia University of Science and Technology (MUST), Malaysia. He is working as Senior Lecturer in the Department of Computing at Middle East College (MEC), Muscat, Oman. His research interests include Learning Analytics, Education Data Mining, BigData and Artificial Intelligence.

Article submitted 2019-07-29. Resubmitted 2019-10-09. Final acceptance 2019-10-09. Final version published as submitted by the authors. 


\section{Appendix 1}

\subsection{Survey Used}

\section{Demographics}

1) Gender

2) Degree program

3) Institute

4) Age

5) Do you have experience of virtual reality / text / video learning before?

6) If yes, how many years of experience of virtual reality / text / video learning do you have?

\section{Value / Usefulness}

1) I believe learning through Text / Video/ VR could be of some value to me.

2) I think that learning through Text/ Video/ VR is useful to me.

3) I would be willing to do this again because it has some value to me.

4) I think this is an important activity.

\section{Perceived Competency}

1) I think I am pretty good at learning through Text/ Video/ VR.

2) I am satisfied with my performance at learning from Text/ Video / VR.

3) I think I did pretty well at this learning from Text/Video/VR, compared to other students.

4) I was pretty skilled at learning through Text/ Video/ VR.

\section{User Experience}

1) I have the impression that text / video learning / virtual reality complements or help to improve my knowledge, skills and experience.

2) I have the impression that text/video/ virtual reality learning complements or help to improve my knowledge, skills and experience.

3) Do you understand the process of laparoscopy through this mode of delivery?

4) The outcome of the virtual reality learning has been according to my level of knowledge.

\section{Motivation}

1) Learning through text/ video/ virtual reality has increased my motivation.

2) I am interested in learning through text/ video/virtual reality.

3) I enjoyed learning through text/ video/ virtual reality

4) I find that learning through text/ video/ virtual reality very motivating. 